\title{
The Geophysical Journal at 25
}

\section{The first satellites and the Geophysical Journal were launched about a quarter of $a$ century ago. Earth sciences continue to benefit from both.}

ONE of the unsurprising oddities of British public life is that the Royal Astronomical Society should also be the publisher of one of the most widely read of British journals in the earth sciences, the Geophysical Journal (with of the Royal Astronomical Socie$t y$ added for formality). The journal is now a mere 25 years old, and has just celebrated its anniversary with a special issue full of review articles celebrating developments in the past quarter of a century (Geophys. $J$. $R$. astr. Soc. 74, 1-376; 1983). There is also a brief introductory note by A.H. Cook and T.F. Gaskell, the founding editors, which is both informative and laconically dissembling. The story as told is interesting; what is left unsaid is absorbing.

In a sense, there always has been a Geophys. J., or there has been since 1921, but it began life as the Geophysical Supplement of the Monthly Notices of the Royal Astronomical Society. That connection is easily understood. Ever since Aristarchus (if it was he) measured the diameter of the Earth, it has been clear that there are some lines of astronomical enquiry that turn back on the Earth. With the vivid interest in the theory of the motion of the Moon, and in tidal theories, towards the end of the nineteenth century, it was natural that astronomers should have acquired an interest in the departures from spherical symmetry of celestial objects and in the distribution of mass within them, and therefore proper that they should have an interest in how things became like that.

Similarly, even after the first editor of Nature was shown to have been mistaken in his belief that the solar corona was a phenomenon in the outer atmosphere of the Earth, astronomers were best fitted to observe a number of terrestrial phenomena - the aurorae and phenomena observable during total solar eclipse.

But where could a mass of material such as this be published? Many fortunately chose Nature, others chose interdisciplinary journals such as Proceedings of the Royal Society and then, from 1921, there was the ponderous device of the Geophysical Supplement. People like the late Sydney Chapman often found it more convenient to write books instead. In Britain, however, the young Sir Harold Jeffreys seems to have been the most persistent problem for editors of publications extant half a century ago. By the standards set for themselves by card-carrying earth scientists, geologists and the like, his work on the internal constitution of the Earth was pure speculation, devoid of observation. But plainly (as it must then have seemed) it had no place in an astronomical journal either. So in a sense there was a need of something like Geophys.J. to accommodate Jeffreys and his school.

By 1958, there were two other developments to contend with - the growing belief that continental drift might be real after all, based largely on palaeomagnetism, which was unpalatably radical for the geological journals, and the rich harvest of the International Geophysical Year.

So was it mere entrepreneurship that persuaded an astronomical society to start a geophysical journal? There is more to the tale than that. A quarter of a century ago, the standard British journals in the earth sciences were unsympathetic and were profoundly suspicious of the people who held that it should be possible to find out about the structure of the Earth with the help of instruments other than the hammer and the microscope. Geophys. $J$, is thus a monument, probably permanent, to an old quarrel which has largely been settled but which is far from forgotten.

Cook (still managing editor of the journal) and Gaskell admit that at the outset, luck was on their side. The launching of the first two sputniks helped them to sell subscriptions to the new journal and also gave them an unexpected stream of material to publish. Fifteen years went by before the geologists were reconciled to the theory of plate tectonics, and one of the persistent ironies is that Jeffreys, whose activities helped to make the need for the journal apparent and whose 70th and 90th birthdays have been celebrated by special issues of Geophys. J., remains disaffected.

The objective of the latest celebration is different - to show how geophysics has changed in a quarter of a century. Cook and Gaskell insist on the importance of improved techniques, and they are surely right. The new techniques include those for observing the motion of Earth satellites, to begin with by straightforward (but far from simple) analysis of their orbital motion, more recently by laser tracking and by radio altimetry from the satellites themselves. King-Hele, from the Royal Aircraft Establishment at Farnborough in Britain was one of the first to recognize what might be wrung out of other people's satellites by careful observation, for which reason it is proper that the first article in this celebratory symposium should be his.

In 1958, the geometrical shape of the sur- face of the Earth was known to within a few metres by means of a blend of astrometry and triangulation. Now, of course, triangulation based on satellite tracks and, potentially even more important, interferometry of distant radio sources, promises to reduce the uncertainties by two orders of magnitude, to a few centimetres at most. With the help of such data the modellers of the Earth's gravitational field make use of a synthetic reference surface of the Earth called the geoid - a surface containing as much mass as the Earth itself, but which is an equipotential surface whose shape is also consistent with the pattern of the gravitational field external to itself.

The best measure of what has been learned since 1958 is provided by the maps of the shape of the geoid which K. Lambeck and R. Coleman contribute to the special issue of Geophys. J. (74, 25-54). They have the effrontery to draw contours at invervals of 3 metres, and conclude that the various estimates so far produced of where the geoid lies are discordant by only a few metres. The point seems to have been reached at which the patterns on the surface of the Earth call for a more tangible interpretation, in terms of mantle convention plumes or spreading ridges, than the plate tectonics people have provided.

The chief interest of this field, however, is still largely technical - how to extract from the data which have accumulated a more complete description of the Earth's gravitational field? Lambeck and Coleman demonstrate convincingly that the tracking of a diversity of satellites, with different altitudes and different orbital inclinations, is essential. It is remarkable how much knowledge of high-order terms in the spherical harmonic of the gravitational field King-Hele and others have extracted from the chance coincidence of some satellite orbit with some resonance caused by the Earth's rotation, bringing some gravitational anomaly around so as to affect a satellite orbit cumulatively.

Yet Lambeck and Coleman's account suggests that the analysis of the data now available is not nearly as systematic as it should be. People seem repeatedly to analyse data provided by a new clutch of satellites, to publish a new Earth model and then turn their attention to something else. Is it too much to hope that somebody will devise and maintain the computer program that will enable this important job to be done systematically?

John Maddox 